\title{
One-year follow-up effects of two obesity treatments on psychological well-being and weight.
}

Citation for published version (APA):

Nauta, H. M., Hospers, H. J., \& Jansen, A. T. M. (2001). One-year follow-up effects of two obesity treatments on psychological well-being and weight. British Journal of Health Psychology, 6, 271-284. https://doi.org/10.1348/135910701169205

Document status and date:

Published: 01/01/2001

DOI:

10.1348/135910701169205

Document Version:

Publisher's PDF, also known as Version of record

Document license:

Taverne

Please check the document version of this publication:

- A submitted manuscript is the version of the article upon submission and before peer-review. There can be important differences between the submitted version and the official published version of record.

People interested in the research are advised to contact the author for the final version of the publication, or visit the DOI to the publisher's website.

- The final author version and the galley proof are versions of the publication after peer review.

- The final published version features the final layout of the paper including the volume, issue and page numbers.

Link to publication

\footnotetext{
General rights rights.

- You may freely distribute the URL identifying the publication in the public portal. please follow below link for the End User Agreement:

www.umlib.nl/taverne-license

Take down policy

If you believe that this document breaches copyright please contact us at:

repository@maastrichtuniversity.nl

providing details and we will investigate your claim.
}

Copyright and moral rights for the publications made accessible in the public portal are retained by the authors and/or other copyright owners and it is a condition of accessing publications that users recognise and abide by the legal requirements associated with these

- Users may download and print one copy of any publication from the public portal for the purpose of private study or research.

- You may not further distribute the material or use it for any profit-making activity or commercial gain

If the publication is distributed under the terms of Article $25 \mathrm{fa}$ of the Dutch Copyright Act, indicated by the "Taverne" license above, 


\title{
One-year follow-up effects of two obesity treatments on psychological well-being and weight
}

\author{
Helga Nauta*, Harm Hospers and Anita Jansen \\ Maastricht University, Maastricht, The Netherlands
}

\begin{abstract}
Objectives. The effectiveness of a cognitive and a behavioural treatment for obese binge eaters and obese non-binge eaters was evaluated at 1-year follow-up. Furthermore, we examined the role of weight changes on psychological well-being at 1-year follow-up.
\end{abstract}

Design and method. Participants were reassessed 6 months and 1 year after they had finished a group cognitive treatment or a group behavioural treatment. The outcome measures were; psychological well-being (concerns about shape, weight and eating, selfesteem and depression), binge eating, and weight.

Results and conclusions. Analyses on the completers' sample revealed that both treatments had a markedly positive and lasting impact on shape concern, weight concern and eating concern, binge eating, self-esteem, and depression at 1-year followup. Cognitive treatment was not superior to behavioural treatment on most outcome measures. This might be due to selective drop-out. Analyses including non-responders showed that the cognitive treatment was superior on shape, weight and eating concern, and binge eating. The 1-year follow-up results for weight-loss were disappointing. Between pre-treatment and 1-year follow-up participants in the behaviour treatment lost $3.0 \mathrm{~kg}$, while participants in the cognitive treatment lost $0.3 \mathrm{~kg}$. However, participants who gained weight were as successful on changes in psychological well-being changes as participants who lost weight.

Behavioural treatments for obese people who focus on weight loss generally succeed in the short term, but are often not very effective in maintaining weight loss in the long term (e.g. Bennett, 1986; Garner \& Wooley, 1991; Wadden, 1993; Wilson, 1994). Despite diverse attempts to improve long-term maintenance, almost all participants return to their baseline weights (e.g. Perri et al., 1987; Perri, Nezu, Patti, \& McCann, 1989; Wilson, 1994). Moreover, several researchers have found that dieting itself has negative effects as well. Frequent dieting might be associated with increased cardiovascular and all-cause mortality (Blair, Shaten, Brownell, Collins, \& Lissner, 1993; Lissner et al., 1991), and results in pathological changes in cognition and affect (Brownell \& Rodin,

* Requests for reprints should be addressed to Helga Nauta, Academic Hospital Maastricht, Department of Psychiatry, PO Box 5800, 6202 AZ Maastricht, The Netherlands (e-mail: helga.nauta@spsy.azm.nl). 
1994; Foreyt et al., 1995; Friedman \& Brownell, 1995; Polivy \& Herman, 1992). The literature is inconclusive as to the causal role that dieting plays in the development of binge eating in obese people (Howard \& Porzelius, 1999). However, in a prospective study of Telch and Agras (1993), it was found that caloric restriction leads to binge-eating episodes in obese people.

This discouraging outcome of obesity treatment and the negative effects of dieting has led to an acknowledgement that weight loss may be an inappropriate first goal for many obese people. There is some evidence that it may be more prudent to focus directly on psychological well-being rather than weight loss. Therefore, researchers and clinicians are beginning to call for non-dieting approaches that focus upon outcome goals other than weight loss (Ciliska, 1990; Garner \& Wooley, 1991; Polivy \& Herman, 1992, Wardle, 1995). The focus of a non-dieting approach will be on the improvement of psychological well-being, body-related attitudes and on restoring normal eating patterns, versus weight loss per se.

Obese individuals presenting for treatment of obesity display a higher prevalence of psychological problems than not seeking treatment (Friedman \& Brownell, 1995; Miller \& Downey, 1999). An important development in the study of obesity is the recognition that between $20 \%$ and $46 \%$ of obese patients seeking treatment report moderate to severe problems with binge eating (Bruce \& Wilfley, 1996; Gormally, Black, Daston, \& Rardin, 1982; Marcus, Wing, \& Lamparski, 1985; Spitzer et al., 1992; Telch, Agras, \& Rossiter, 1988). This subgroup of obese individuals displays even more severe psychological problems than obese non-binge eaters. Obese binge eaters show more concerns about shape, weight, and eating than obese non-binge eaters (Eldredge \& Agras, 1996; Wilson, Nonas, \& Rosenblum, 1993), at levels that are comparable to those mentioned by bulimia nervosa patients (Marcus, Smith, Santelli, \& Kaye, 1992). Furthermore, individuals with binge eating disorder are more vulnerable to depression (Hudson et al., 1988; Kuehnel \& Wadden, 1994; Marcus, Wing, Hopkins, 1988; Mussell et al., 1996; Spitzer et al., 1992; Telch \& Agras, 1994; Wadden, Foster, \& Letizia, 1994; Yanovski, Nelson, Dubbert, Spitzer, 1993) and have a lower self-esteem (De Zwaan et al., 1994; Telch \& Agras, 1994) than obese non-binge eaters.

Focusing on psychological well-being, restoring body-related attitudes and nondieting might lead to more lasting improvements and might have positive effects on weight in the long run than dieting approaches, considering that caloric restriction is an important determinant of binge eating or overeating. A non-dieting approach will be advantageous over dieting approaches in the treatment of obesity and obese binge eaters in particular. Improvement of psychological well-being might decrease over-eating elicited by feeling bad and, in that way, facilitate weight loss.

Long-term follow-up results of non-dieting approaches for obese people have rarely been reported. To date, only five studies of non-dieting treatments have reported followup results of 1 year or more. Of these, two focused on a modified behavioural treatment with cognitive elements for obese binge eaters and obese non-binge eaters (Marcus et al., 1988; Porzelius, Houston, Smith, Arfken, \& Fisher, 1995), and three studies reported results of cognitive-behavioural treatment for obese binge eaters in particular (Agras, Telch, Arnow, Eldredge, \& Marnell, 1997; Goodrick, Poston, Kimball, Reeves, \& Foreyt, 1998; Wilfley et al., 1993). A central prediction of the cognitive model is that weight loss will not take place, and binge eating will follow as concerns about shape, weight, and 
eating are maintained or increased (Fairburn, Marcus, \& Wilson, 1993). The primary outcome measures in the aforementioned studies were weight loss and, in the case of obese binge eaters, frequency of binge eating. Interestingly, attitudes towards shape, weight, and eating were not reported. In three studies, objective binge episodes were measured, and in all these studies, a reduction in objective binge episodes was found, in the short and long term (Agras et al., 1997; Porzelius et al., 1995; Wilfley et al., 1993). The results were less clear concerning weight loss. Weight loss tended to be regained at long-term follow-up (Goodrick et al., 1998; Marcus et al., 1998; Wilfley et al., 1983). However, Agras et al. (1997) found that those who stopped binge eating at post-treatment maintained their weight loss over the follow-up period, while those who continued to binge regained weight. Porzelius et al. (1995) found that 1 year after cognitive-behavioural treatment, women who were categorized as severe binge eaters at pre-treatment continued to lose weight, while women who were categorized as non-binge eaters stopped losing weight.

To the present authors' knowledge, it has never been tested whether improvement in general well-being is related to weight loss in the long term. In the present study, the authors predicted that improving psychological well-being and normalizing eating patterns of participants would finally be related to weight loss. It was hypothesised that: (1) at 1-year follow-up, the cognitive treatment would be more effective than the behavioural treatment in improving psychological well-being (concerns about shape, weight and eating, self-esteem and depression); (2) at 1-year follow-up, the improvement in psychological well-being might be related to weight loss.

\section{Method}

\section{Participants}

The selected participants were 74 obese and overweight women. They were recruited from a group of respondents answering local newspaper advertisements that offered two university-based treatments for eating problems. Inclusion criteria were: age between 18 and 50 years, and a BMI of 27 or higher. Exclusion criteria were: participation in a weight-loss program at the time of selection, current physical dependence on alcohol or drugs, psychosis, or pregnancy.

Obese and overweight women who responded to the advertisements were screened for the inclusion and exclusion criteria in a telephone interview. Interested and potentially eligible individuals $(N=451)$ received the revised Questionnaire on Eating and Weight Pattern (QEWP-r; Yanovski, 1993). This self-report questionnaire contains 28 items and is designed to collect information regarding demographics, weight history, dieting history, and psychiatric and medical history. The questionnaire also contains items that specifically test for the Diagnostic and Statistical Manual of Mental Disorders (DSM-IV; American Psychiatric Association, 1994) criteria for Binge Eating Disorder (BED). Furthermore, questions on inclusion and exclusion criteria were added. After completion at home, the questionnaires were returned to the university $(N=265)$.

If respondents met the BED criteria or did not have any binge episodes at all, they $(N=145)$ were invited for a structured diagnostic interview that lasted about $1 \mathrm{~h}$ and was conducted by a psychologist experienced in the assessment of eating disorders and obesity. The interviewer clarified and checked the DSM-IV items, especially those regarding quantity of food and extent of loss of control, and the exclusion criteria were checked once again. After the diagnostic interview, participants were weighed in street clothes, without shoes, on a balance beam scale, and their height was measured. The purpose of the study was explained, and written informed consent for the treatment program was obtained.

Respondents were categorized as non-binge eaters if they fulfilled none of the DSM-IV criteria for BED. The BED diagnosis was made if respondents met strict DSM-IV criteria for the disorder. The present authors anticipated that comparing two extreme groups would be most likely to reveal relevant differences. 
Therefore, the major reason for exclusion was if respondents met some of the DSM-IV criteria, but not all. Other individuals cancelled the interview appointment or did not appear at the interview, or decided not to participate in the program, primarily for practical reasons. Finally, 37 women who met the proposed DSM-IV criteria for BED and 37-binge eaters made up the definitive sample.

\section{Study design}

An experimental design was chosen, consisting of a pre- and a post-measurement, and two follow-up measurements at 6 months and 1 year after treatment. Participants were recruited in two equal phases and were randomly assigned to one of the two treatment conditions, with binge status taken into account. Thus, this procedure resulted in four distinct groups: non-binge eaters who received behaviour treatment, binge eaters who received behaviour treatment, non-binge eaters who received cognitive treatment, and binge eaters who received cognitive treatment.

Selected participants were asked to complete questionnairesat home before treatment, after treatment, and 6 months and 1 year after treatment. During an interview at the university, it was checked whether all items on the questionnaires had been filled in, frequency of overeating was measured with the help of a 28-day interview method (Fairburn \& Cooper, 1993), and participants' weights were obtained.

\section{Treatment}

General aspects. Both treatments were given in groups, and all groups met for 15 weekly sessions of $150 \mathrm{~min}$ each. Ten groups, each consisting of 7 or 8 participants were assisted by one therapist. Eight therapists, experienced in the behavioural and cognitive treatment of eating disorders and/or obesity, participated in this study, each facilitating the treatment of at least one group. If therapists guided one treatment condition, they were randomly assigned to $\mathrm{CT}$ or $\mathrm{BT}$ condition. If a therapist guided two treatment conditions, they conducted a CT and BT group. For both conditions, detailed treatment protocols were developed. All therapists received an intensive training in the protocol. Weekly consultation sessions of approximately $1 \mathrm{~h}$ with each therapist were held to ensure therapists' compliance with treatment protocols. The common features in both treatments were semi-structured and problem-oriented, primarily concerned with the participants present and future rather than past, they provided a coherent treatment rationale, and they were self-monitoring and set homework assignments.

Cognitive treatment $(C T)$. The aim of this treatment was to change dysfunctional cognitions regarding shape, weight, eating, dieting, and underlying self-schemas with the help of the cognitive techniques outlined by Beck (1976). In the first session, the therapists explained the rationale of cognitive therapy. A binge/overeating circle was described as beginning with dysfunctional cognitions about shape, weight, eating, dieting, or negative self-schemas. Participants were instructed to self-monitor situations that triggered binge eating or over-eating, and participants had to describe their thoughts. Examination of this monitoring was an important focus of therapy. During the first half of the therapy session, the homework assignments of the participants were discussed. In the second half, participants practised identifying and challenging dysfunctional cognitions and setting up behavioural experiments.

The first stage of the therapy (six sessions), focused on identifying and altering dysfunctional cognitions regarding shape, weight, and eating. The Socratic dialogue was used by the therapist to initialize active learning and to encourage a questioning, investigate attitude in the participants. Furthermore, participants were encouraged to engage in behavioural experiments designed to challenge their dysfunctional cognitions.

In the second stage (six sessions), cognitive techniques directed at identifying and challenging negative self-schemas that perpetuated disordered eating were emphasized. Negative self-schemas were identified and challenged, and behavioural experiments were also used. Examples of negative self-schemas were: 'If I go to the swimming pool, people will reject me' or 'If I gain weight, I will be worthless'.

The final stage (three sessions) was largely concerned with the maintenance of progress following the end of treatment. Marlatt and Gordon (1985) proposed that the Abstinence Violation Effect (AVE) accounts for some of the variability regarding relapse. The AVE model predicts that internal, stable, and global attributions for a lapse increase the probability of over-eating or binge eating. Participants were informed that lapses were normal and to be expected. The purpose of the cognitive restructuring procedure in the last phase was to reframe maladaptive attributions of causality regarding lapses, to make it easier to regain control. 
Behavioural treatment (BT). The aim of the behavioural treatment was to learn a healthy eating pattern by having three meals each day and three planned snacks, decreasing fat intake, eating about $1500-1800 \mathrm{kcal}$ a day, increasing exercise habits, and recognizing and anticipating high-risk situations.

In the first session, the therapists explained the rationale of behavioural therapy. To regain control over eating, it is important to learn a healthy eating pattern, without excessive restrictive dieting. Participants were told that treatment first needed to eliminate binge eating and over-eating patterns by establishing regular, healthy eating patterns and that weight control needed to be a secondary concern.

Participants were told to self-monitor their food intake and eating patterns, binge episodes or episodes of over-eating and the circumstances under which they occurred, such as time, presence of other people, and mood. Examination of the self-monitoring formed an important focus of therapy. In the first half of the session, homework assignments were discussed and in the second half, nutritional information was given. Furthermore, participants were advised to make gradual changes in eating habits and exercise levels. Therefore, weekly goals were set to change their eating habits, exercise level, and general activity levels. The basic behavioural strategies were self-monitoring, goal-setting, and stimulus control techniques. Three forms of stimulus control techniques were used. First, participants learned stimulus-control techniques, whereby stimuli that resulted in eating were avoided (e.g. not buying food, not going to a shop when hungry). Second, they learned techniques to anticipate high-risk situations and to outline strategies to prevent eating, such as walking, talking with friends, or taking a shower. Third, participants learned self-reinforcement techniques, such as going to the cinema or buying a magazine, and were positively reinforced by the therapist if they were not over-eating. No attention was paid to dysfunctional cognitions.

\section{Dependent variables}

Eating pathology. This was measured with the Eating Disorder Examination Questionnaire(EDE-Q; Fairburn \& Beglin, 1994). The EDE-Q is a 36-item self-report questionnaire version of the Eating Disorder Examination investigator-based interview, the so-called Eating Disorder Examination (EDE; Fairburn \& Cooper, 1993). The EDE-Q is designed to assess the specific core psychopathology of eating disordered individuals and focuses on the previous 28 days. Four subscales of the EDE-Q were used: Shape Concern, Weight Concern, Eating Concern, and Restraint. Wilfley, Schwartz, Spurrell, and Fairburn (1997) found a modest to good agreement between the self-report version and the investigator-based interview on these four subscales. However, they found little agreement when assessing binge eating. It was suggested that the performance of the EDE-Q would be improved by clarifying the definitions of complex features, such as binge eating, with the help of an additional interview. Therefore, binge eating was assessed with the help of the interview method. Since Rossiter, Agras, Telch, and Bruce (1992) proposed that recollecting the days with binge eating episodes is performed more accurately than recollecting the number of binge eating episodes, we measured the number of days in which an objective binge episode had occurred during the last 28 days.

Weight. Participants were weighed in street clothes, without shoes, on a balance beam scale.

Depression. This was measured with the Beck Depression Inventory (BDI; Beck, Ward, Mendelson, Mock, \& Erbaugh, 1961). The BDI is a 21-item self-report measure of severity of depressive symptomatology. The items are rated on a 4-point scale ranging from 0 ('not depressed') to 3 ('severely depressed'), resulting in a range of scores from 0 to 63 . Higher scores indicate more severe depression.

Self-esteem. This was measured with Rosenberg's Self-Esteem Scale (RSE; Rosenberg, 1965), a 10-item questionnaire measuring global self-esteem, with special reference to the self-evaluation of the individual regarding an attitude of approval or disapproval. Each item is scored on a 4-point scale ranging from strongly agree to strongly disagree, resulting in a range from 0-40. A lower score indicates more positive self-esteem.

\section{Statistical procedure}

The dependent variables were divided into eating pathology (dietary restraint and concerns about shape, weight, and eating), binge eating, weight, and generic psychopathology (depression and self-esteem). To 
investigate the long-term effectiveness of both treatments, the results were analysed with 2 (Treatment: BT versus CT) $\times 2$ (Binge Status: obese binge eaters versus obese non-binge eaters) $\times 2$ (Time: pre-treatment, 1 year follow-up) repeated-measures multivariate and univariate analyses of variance. In addition, we examined if there was relapse between 6-month and 1-year follow-up. Therefore, all analyses were repeated using the 6month and 1-year follow-up scores on the dependent variables. Analyses were performed for the participants who completed treatment and excluding non-responders \{completers'sample $(N=60)\}$ and for participants who completed treatment including non-responders $(N=64)$.

\section{Results}

\section{Drop-out during treatment and follow-up}

Ten $(13.5 \%)$ participants from a total of 74 dropped out of treatment ('treatment dropouts'): three binge eaters and two non-binge eaters from the CT group, and three binge eaters and two non-binge eaters from the BT group. Reasons that participants gave for dropping out were: not losing enough weight $(N=4)$, travelling time $(N=2)$, and disruptive life events $(N=4)$. Drop-out rates did not differ between cognitive and behavioural treatments, or between binge eaters and non-binge eaters. If individuals declined to complete follow-up assessments, they were considered as non-responders. At 6-month follow-up, there were no non-responders. However, at 1-year follow-up, four women refused to take part in the assessment. All four women had received behavioural treatment, and three of them were binge eaters. They agreed to a short telephone interview in which reasons for non-response and frequency of binge eating were explored. The reasons for non-response were that they were all disappointed in the behavioural treatment and were not motivated to fill in the questionnaires and to visit the university. The obese binge eaters had bulimic symptoms, and the obese non-binge eaters reported a chaotic eating pattern and severe depressive symptoms. In total, $14(18.9 \%)$ of the 74 participants dropped out of treatment or were non-responders at 1-year follow-up: three binge eaters and two non-binge eaters from the CT group and six binge eaters and three non-binge eaters from the BT group. T-tests were conducted on demographic variables and outcome measures at pre-treatment (age, duration of obesity, duration of binge eating, weight, binge eating, eating concern, weight concern, shape concern, restraint, self-esteem, and depression). Obese binge eaters who dropped out of treatment or were non-responders had a significantly lower self-esteem $\{t(35)=2.33, p<.05\}$ and more shape concern $\{t(35)=2.07, p<.05\}$ than the other obese binge eaters. Obese non-binge eaters who dropped out of treatment or were non-responders were heavier $\{t(35)=2.09, p<.05\}$ than the other obese non-binge eaters. On all other variables, no differences were found. Participants who were non-responders or dropped out of behavioural treatment had a lower self-esteem $\{t(35)=2.25, p<.05\}$ than the other participants in the behavioural treatment. Participants who were non-responders or dropped out of cognitive treatment also had a lower self-esteem $\{t(35)=2.16, p<.05\}$ than the other participants in the cognitive treatment. On all other variables, no differences were found.

At pre-treatment, the mean age of the completer's sample was 38.6 years $(\mathrm{SD}=6.6)$. The mean BMI was $33.0(\mathrm{SD}=4.2)$, with a range between 29.0 and 45.2. The mean $\mathrm{BMI}$ of participants in the behavioural treatment was 33.7 and in the cognitive treatment 
32.4. Of the sample, $77 \%$ was obese (BMI > 30), and $23 \%$ of the sample had a BMI between 27 and 30 .

Participants reported a mean duration of obesity of 21.2 years $(S D=8.5)$. Binge Eating Disorder patients reported a mean frequency of binge eating of 4 days per week $(\mathrm{SD}=1.7)$. The mean duration of their binge eating was 13.5 years $(\mathrm{SD}=6.5)$.

Dietary restraint and concerns about shape, weight, and eating

Table 1 shows the means and standard deviations for all outcome measures at pretreatment, 6-month follow-up and at 1-year follow-up for the completers' sample. The repeated-measures MANOVA performed on the pre-treatment and 1-year follow-up scores on the four subscales of the EDE-Q showed a significant multivariate effect for Time $\{F(4,54)=46.70, p<.001\}$. Univariate ANOVAs revealed that three of the four subscales showed significant Time effects $(p<.001)$, including an improvement on shape, weight, and eating concerns. There was no significant effect for restraint. Furthermore, there was a trend for a multivariate Treatment $\times$ Time interaction, between pretreatment and 1-year follow-up $\{F(4,54)=2.14, p=.09\}$. Additional univariate anayses revealed a significant Time $\times$ Treatment interaction for weight concern $\{F(1,57)=7.84, p<.01\}$. For lasting positive effects on weight concern, the cognitive treatment proved to be more potent than the behavioural treatment. There were no significant Time $\times$ Treatment interactions for the subscales shape concern, eating concern and restraint. Finally, there was a significant Time $\times$ Binge Status effect between pretreatment and 1-year follow-up $\{F(4,54)=6.85, p<.001\}$. Three subscales revealed significant univariate Time $\times$ Binge Status interactions: shape concern $\{F(1,57)=12.36$, $p<.001\}$, weight concern $\{F(1,57)=10.75, p<.01\}$, and eating concern $\{F(1,57)=27.94$, $p<.001\}$. The restraint subscale showed a trend for a Time $\times$ Binge Status interaction $\{F(1.57)=3.71, p=.06\}$. Inspection of the means revealed that binge eaters had improved more than non-binge eaters.

A MANOVA performed on the four subscales of the EDE-Q between 6-month followup and 1-year follow-up revealed no significant multivariate effects for Time, or for Time $\times$ Treatment of Time $\times$ Binge Status. Between 6-month follow-up and 1-year follow-up, the positive impact on the four subscales of the EDE-Q was maintained.

\section{Weight}

Results of the 2 (Treatment) $\times 2$ (Binge Status) $\times 2$ (Time: pre-treatment versus 1 -year follow-up) repeated-measures ANOVA performed on the scores for weight yielded a significant effect for Time $\{F(1,57)=5.92, p<.01\}$. Furthermore, there was a trend for a Time $\times$ Treatment interaction $\{F(1,57)=3.59, p=.06\}$. Between pre-treatment and 1-year follow-up, participants in the behaviour treatment lost $3.0 \mathrm{~kg}$, while participants in the cognitive treatment lost $0.3 \mathrm{~kg}$. There was no significant effect for Time $\times$ Binge Status.

Results of the 2 (Treatment) $\times 2$ (Binge status) $\times 2$ (Time: 6-month follow-up versus 1-year follow-up) repeated-measures ANOVA performed on the scores for weight showed neither significant effects for Time nor significant effects for Time $\times$ Treatment and Time $\times$ Binge Status. 

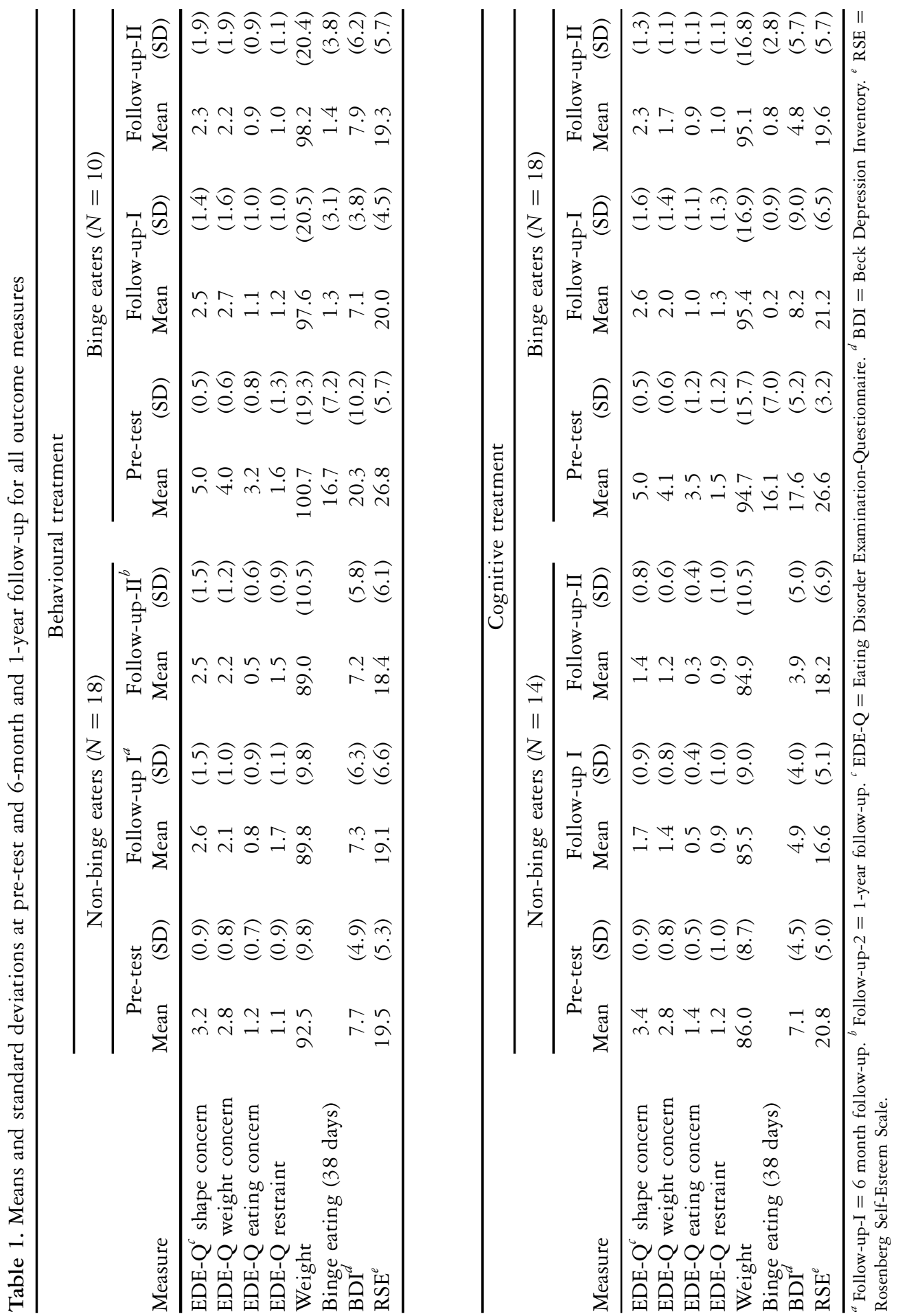


\section{Binge eating}

A 2 (Treatment) $\times 2$ (Time: pretreatment versus 1 -year follow-up) repeated-measures ANOVA using the number of objective binge episodes resulted in a significant main effect for Time $\{F(1,26)=104.27, p<.001\}$. No significant interaction effect for Time $\times$ Treatment was found. Both treatments had a lasting impact on the reduction of binge eating. At 1-year follow-up, the cognitive treatment had reduced bingeing by $95 \%$, and the behavioural treatment had reduced bingeing by $91 \%$. At 1-year follow-up, $83 \%$ of the participants in the cognitive condition and $70 \%$ of the participants in the behavioural treatment abstained from binge eating. Furthermore, one obese binge eater in the behavioural treatment and one obese binge eater in the cognitive treatment fulfilled the DSM-IV criteria for binge eating disorder.

A 2 (Treatment) $\times 2$ (Time: 6-month follow-up versus 1 -year follow-up) repeatedmeasures ANOVA using the number of objective binge episodes resulted in neither a significant Time effect nor a significant Time $\times$ Treatment interaction effect. The reduction in binge episodes was maintained between the 6-month and 1-year follow-up.

\section{Depression and self-esteem}

A 2 (Treatment) $\times 2$ (Binge Status) $\times 2$ (Time: pre-treatment versus 1 -year follow-up) MANOVA performed on the BDI and RSE showed a significant multivariate effect for Time $\{F(2,56)=37.88, p<.001\}$. Univariate analyses on the pre-treatment and 1-year follow-up scores showed significant Time effects on depression $\{F(1,57)=75.24$, $p<.001\}$ and self-esteem $\{F(1,57)=47.26, p<.001\}$. Participants were less depressed and had a higher self-esteem between pre-treatment and 1-year follow-up. There was no significant multivariate interaction effect for Time $\times$ Treatment between pre-treatment and 1-year follow-up. Finally, there was a multivariate interaction effect for Time $\times$ Binge Status $\{F(2,56)=20.21, p<.001\}$ between pre-treatment and 1 -year follow-up. Additional univariate analyses showed significant Time $\times$ Binge Status effects on depression $\{F(1,57)=41.02, p<.001\}$ and self-esteem $\{F(1,57)=16.62, p<.001\}$.

The 2 (Treatment) $\times 2$ (Binge Status) $\times 2$ (Time: 6 -month versus 1 -year follow-up) MANOVA performed on the BDI and RSE showed a significant multivariate effect for Time $\times$ Treatment $\{F(2,56)=3.56, p<.05\}$. Additional univariate analyses showed a trend for a Treatment $\times$ Time effect for depression $\{F(1,57)=3.80, p=.06\}$, but not for self-esteem. The cognitive treatment was superior to the behavioural treatment in reducing depression between the 6-month and 1-year follow-up. There were no significant effects for Time and Time $\times$ Binge Status.

\section{Analyses including non-responders}

Ten participants dropped out of treatment, and between the 6-month follow-up and 1 -year follow-up, four participants in the behavioural treatment refused to participate in the 1-year follow-up assessment. The results presented so far might be influenced by selective drop-out. Therefore, additional end-point analyses were repeated on all outcome variables in which the missing values of the four treatment non-responders were replaced with the last scores available (6-month follow-up). There were differences between these end-point analyses and the analyses discussed earlier for the completer's sample. The 
repeated-measures MANOVA performed on the pre-treatment and 1-year follow-up scores on the four subscales of the EDE-Q now showed a significant multivariate interaction effect for Time $\times$ Treatment $\{F(4,58)=3.35, p<.01\}$. Additional univariate analyses revealed Treatment $\times$ Time interactions for shape concern $\{F(1,61)=5.71$, $p<.01)\}$; weight concern $\{F(1,61)=12.82, p<.001\}$ and a trend for eating concern $\{F(1,61)=3.23, p=.06\}$; there was no effect for restraint. Participants in the cognitive treatment showed a stronger reduction on these concerns than participants who received behavioural treatment between pre-treatment and 1-year follow-up. A greater percentage of the participants in the cognitive condition were abstinent from binge eating (83\%), as compared to participants who received behavioural treatment (54\%). A Fisher exact test revealed a trend that the proportion of participants abstaining from binge eating at follow-up in the cognitive treatment was higher than in the behavioural group $(p=.08)$. It is notable that all three non-responders in the behavioural treatment still fulfilled the criteria for BED at one-year follow-up. Furthermore, there were no essential differences between the analyses including nonresponders and the completer's analyses.

\section{Relationship between weight and psychological well-being}

Additional analyses were conducted with the completer sample to determine whether those participants who lost weight showed any more improvement on psychological variables than participants who gained weight. Participants were divided into two groups on the basis of weight loss between pre-treatment and 1-year follow-up \{participants who gained weight $(N=24)$ and participants who lost weight $(N=36)$ \}. Success or failure at weight loss was used as a between-group factor, and time was used as a repeated measure in ANOVAs for shape concern, weight concern, eating concern, depression, and selfesteem. We were interested in the interaction effects between psychological well-being and weight. The analyses showed no significant interaction effects between participants who gained weight and participants who lost weight between pre-treatment and 1-year follow-up on psychological outcome measures. Table 2 presents the means and standard deviations on psychological well-being for participants who lost weight and gained weight.

\section{Discussion}

The first hypothesis tested was that the cognitive treatment would be more effective than the behavioural treatment at improving psychological problems at 1-year follow-up. The results of this study showed that for obese binge eaters and obese non-binge eaters, both treatments had a markedly positive and lasting impact on shape concern, weight concern and eating concern, binge eating, self-esteem, and depression at 1-year follow-up. The cognitive and behavioural treatments were both equally successful on most outcome measures at 1-year follow-up. However, the results may be influenced by selective dropout. Participants who did poorly in the behavioural treatment became non-responders at 1 -year follow-up. The analyses including non-responders showed that the cognitive treatment was superior in improving shape, weight and eating concern, and binge eating at 1-year follow-up. In addition, it was tested whether there was relapse between 
Table 2. Means and standard deviation at pre-treatment and 1-year follow-up for participants who lost weight and regained weight on psychological outcome measures

\begin{tabular}{|c|c|c|c|c|c|c|c|c|}
\hline \multirow[b]{3}{*}{ Measures } & \multicolumn{4}{|c|}{$\begin{array}{c}\text { Participants who } \\
\text { lost weight }(N=36)\end{array}$} & \multicolumn{4}{|c|}{$\begin{array}{l}\text { Participants who } \\
\text { regained weight }(N=24)\end{array}$} \\
\hline & \multicolumn{2}{|c|}{ Pre-treatment } & \multicolumn{2}{|c|}{$\begin{array}{l}\text { 1-year } \\
\text { follow-up }\end{array}$} & \multicolumn{2}{|c|}{ Pre-treatment } & \multicolumn{2}{|c|}{$\begin{array}{l}\text { 1-year } \\
\text { follow-up }\end{array}$} \\
\hline & Mean & $(\mathrm{SD})$ & Mean & $(\mathrm{SD})$ & Mean & $(\mathrm{SD})$ & Mean & $(\mathrm{SD})$ \\
\hline $\mathrm{EDE}-\mathrm{Q}^{a}$ shape concern & 3.9 & $(0.2)$ & 1.8 & $(0.2)$ & 4.3 & $(0.2)$ & 2.7 & $(0.3)$ \\
\hline EDE-Q weight concern & 3.2 & $(0.2)$ & 1.5 & $(0.2)$ & 3.7 & $(0.2)$ & 2.3 & $(0.2)$ \\
\hline EDE-Q eating concern & 2.1 & $(0.2)$ & 0.5 & $(0.1)$ & 2.5 & $(0.3)$ & 0.9 & $(0.2)$ \\
\hline $\mathrm{BDI}^{b}$ & 10.4 & $(1.3)$ & 4.7 & $(0.9)$ & 15.8 & $(1.6)$ & 7.5 & $(1.1)$ \\
\hline $\mathrm{RSE}^{c}$ & 22.6 & $(1.0)$ & 17.9 & $(1.0)$ & 24.0 & $(1.8)$ & 20.3 & $(1.2)$ \\
\hline
\end{tabular}

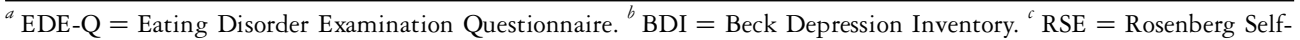
Esteem scale.

6-month and 1-year follow-up. On almost all outcome measures, the positive effects were maintained between 6-month and 1-year follow-up. Only for depression did participants in the cognitive condition become significantly less depressed than participants in the behaviour therapy between 6-month and 1-year follow-up.

The second hypothesis tested was that at 1-year follow-up, an improvement in psychological well-being was related to weight loss. Shape concern, weight concern, eating concern, self-esteem, and depression were greatly improved between pre-treatment and 1-year follow-up. However, participants who gained weight were as successful on psychological mood changes as participants who lost weight. This finding is similar to that reported by Marcus et al. (1988). It could not be demonstrated that improvement in psychological well-being was related to weight loss at 1-year follow-up. In this study, most obese women had made several attempts at weight loss without long-term success, and the women were unhappy with their figure and weight, were not severely obese, had poor self-esteem and a chaotic eating pattern, and were tired of dieting. Non-dieting treatments might be useful for obese people who share these characteristics. Furthermore, for obese binge eaters, both treatments had a lasting effect on reducing binge eating, and $70 \%$ (BT) and $83 \%$ (CT) were abstinent at 1-year follow-up. Further research will need to explore whether it is better to improve psychological well-being first and whether weight loss should become a focus of treatment only after psychological well-being has improved or vice versa.

Little research has been done on the maintenance of change after non-dieting approaches to obesity. Primary outcome measures have mostly been frequency of binge eating and weight loss, and not attitudes to shape, weight, and eating. With regard to binge eating, the present study showed that at 1-year follow-up, $83 \%$ of the obese binge eaters in the cognitive condition and $70 \%$ of the binge eaters in the behavioural treatment abstained from binge eating. A study of Agras et al. (1997) found that 33\% abstained from binge eating 1 year after receiving cognitive-behavioural treatment. Furthermore, in this study, it was found that participants who received cognitive treatment had reduced bingeing by $95 \%$, and participants who received behavioural treatment had reduced bingeing by $91 \%$. Other studies, which evaluated the results of a 
cognitive-behavioural treatment at 1-year follow-up, found a reduction in binge eating of between 55\% and 64\% (Agras et al., 1997; Wilfley et al., 1993). The purely cognitive or behavioural treatments were at least as if not more, effective, than the multicomponent cognitive-behavioural treatment. A possible explanation for this effect is that participants in unifaceted treatments learn and implement the techniques better than participants in more multifaceted treatment packages.

Obesity researchers have suggested that long-term weight losses of $10 \%$ of initial body weight are an appropriate treatment goal (Institute of Medicine, 1995). Bearing this in mind, long-term weight losses in our study were discouraging. Between pre-treatment and 1-year follow-up, participants in the behavioural treatment lost $3.0 \mathrm{~kg}$, while participants in the cognitive treatment lost $0.3 \mathrm{~kg}$. The results are more or less comparable to weight losses achieved in some previous studies using the CBT program and other non-dieting behavioural programs of the same duration (Agras et al., 1997; Goodrick et al., 1998; Marcus et al., 1988; Wilfley et al., 1993). In a study by Porzelius et al. (1995), obese women with severe binge eating problems lost most weight in the cognitive-behavioural treatment, and weight loss for obese women with no binge eating problems did not differ between the treatments at 1-year follow-up. In our study, we found no interaction effect for type of treatment and binge status.

In interpreting the results of this study, certain potential limitations of this study should be considered. A first limitation of this study was the lack of a no-treatment control group, so the beneficial effects of this study may be due to a placebo effect. However, other controlled studies showed that behavioural treatments are superior to a no-treatment control group (for a review, see Wilfley \& Cohen, 1997). Furthermore, it is difficult to find a placebo control group that mimics the tested treatment in all ways, except the putative active factor (Omer \& London, 1989).

Obese binge eaters, as the most common eating disorder, and obese non-binge eaters form a large group of potential health-care consumers. Carter and Fairburn (1998) mentioned that it is unlikely that there will be sufficient specialist resources to deal with the whole population of obese binge eaters and obese non-binge eaters. Therefore, it is important that specialists in primary health care can also deal with obese binge eaters as well as obese non-binge eaters. It might be concluded from this study that an intensive cognitive intervention is not necessary for a subgroup of obese binge eaters and obese non-binge eaters at 1-year follow-up, the cognitive treatment and behavioural treatment were equally effective on psychological well-being. However, there is also a large percentage of obese individuals who did not respond to behavioural treatment.

\section{References}

Agras, W. S., Telch, C. F., Arnow, B., Eldredge, K., \& Marnell, M. (1997). One-year follow-up of cognitivebehavioral therapy for obese individuals with binge eating disorder. Journal of Consulting and Clinical Psychology, 65, 343-347.

American Psychiatric Association (1994). Diagnostic and statistical manual of mental disorders (4th ed.). Washington, DC: Author.

Beck, A. T. (1976). Cognitive therapy and the emotional disorders. New York: International Universities Press. Beck, A. T., Ward, C. H., Mendelson, M., Mock, J., \& Erbaugh, J. (1961). An inventory for measuring depression. Archives of General Psychiatry, 4, 561-571.

Bennett, G. A. (1986). Behavior therapy for obesity: A quantitative review of the effects of selected treatment characteristics on outcome. Behavior Therapy, 17, 554-562. 
Blair, S. N., Shaten, J., Brownell, K., Collins, G., \& Lissner, L. (1993). Body weight change, all-cause mortality, and case specific mortality in the Multiple Risk Factor Intervention Trial. Annals of Internal Medicine, 119, 749-757.

Brownell, D. D., \& Rodin, J. (1994). The dieting maelstrom: Is it possible and advisable to lose weight? American Psychologist, 49, 781-791.

Bruce, B., \& Wilfley, D. (1996). Binge eating among the overweight population: A serious and prevalent problem. Journal of the American Dietetic Association, 96, 58-61.

Carter, J. C., \& Fairburn, G. (1998). Cognitive-behavioral self-help for binge eating disorder: A controlled effectiveness study. Journal of Consulting and Clinical Psychology, 16, 616-621.

Ciliska, D. (1990). Beyond dieting. Psycho educational interventions for chronically obese women: A non-dieting approach. New York: Brunner/Mazel.

De Zwaan, M., Mitchell, J. E., Seim, H. C., Specker, S. M., Pyle, R. L., Raymond, N. C., \& Crosby, R. B. (1994). Eating related and general psychopathology in obese females with binge eating disorder. International Journal of Eating Disorders, 15, 43-52.

Eldredge, K. L., \& Agras, W. S. (1996). Weight and shape overconcern and emotional eating in binge disorder. International Journal of Eating Disorders, 19, 73-82.

Fairburn, C. G., \& Beglin, S. J. (1994). Assessment of eating disorders. Interview or self-report questionnaire? International Journal of Eating Disorders, 16, 363-370.

Fairburn, C. G., \& Cooper, C. (1993). The Eating Disorder Examination (12th edition). In C. G. Fairburn \& G. T. Wilson (Eds.), Binge eating: Nature, assessment, and treatment (pp. 317-360). New York: Guilford Press.

Fairburn, C. G., Marcus, M. D., \& Wilson, G. T. (1993). Cognitive-behavioral therapy for binge eating and bulimia nervosa: A comprehensive treatment manual. In C. G. Fairburn \& G. T. Wilson (Eds.), Binge eating: Nature, assessment, and treatment (pp. 361-404). New York: Guilford Press.

Foreyt, J. P., Brunner, R. L., Goodrick, G. K., Cutter, G., Brownell, K. D., Jeor, S. T. (1995). Psychological correlates of weight fluctuation. International Journal of Eating Disorders, 17, 253-275.

Friedman, M. A., \& Brownell, K. D. (1995). Psychological correlates of obesity: Moving to the next research generation. Psychological Bulletin, 117, 3-20.

Garner, D. M., \& Wooley, S. C. (1991). Confronting the failure of behavioral and dietary treatments for obesity. Clinical Psychology Review, 11, 729-780.

Goodrick, G. K., Poston, W. S., Kimball, K. T., Reeves, R. S., \& Foreyt, J. P. (1998). Nondieting versus dieting treatment for overweight binge-eating women. Journal of Consulting and Clinical Psychology, 66, 363-368.

Gormally, J., Black, S., Daston, S., \& Rardin, D. (1982). The assessment of binge eating severity among obese persons. Addictive Behaviors, 7, 47-55.

Howard, C. E., \& Porzelius, L. K. (1999). The role of dieting in binge eating: Etiology and treatment implications. Clinical Psychology Review, 19, 25-44.

Hudson, J. I., Pope, H. G., Wurtman, J., Yurgelun-Todd, D., Mark, S., \& Rosenthal, N. E. (1988). Bulimia in obese individuals: Relation to normal weight bulimia. The Journal of Nervous and Mental Disease, 176, $144-152$.

Institute of Medicine (1995). Weighing the options: Criteria for evaluating weight management programs. Washington, DC: National Academy Press.

Kuehnel, R. H., \& Wadden, T. A. (1994). Binge eating disorder, weight cycling, and psychopathology. International Journal of Eating Disorders, 15, 321-329.

Lissner, L., Odell, P. M., D’Agostino, R. B., Stokes, J., Kreger, B. E., Belanger, A. J., \& Brownell, K. D. (1991). Variability in body weight and health outcomes in the Framingham population. New England Journal of Medicine, 324, 1839-1844.

Marcus, M. D., Smith, D., Santelli, R., \& Kaye, W. (1992). Characterization of eating disordered behavior in obese binge eaters. International Journal of Eating Disorders, 12, 249-255.

Marcus, M. D., Wing, R. R., \& Hopkins, J. (1988). Obese binge eaters: Affect, cognitions, and response to behavioral weight control. Journal of Consulting and Clinical Psychology, 56, 433-439.

Marcus, M. D., Wing, R. R., \& Lamparski, D. M. (1985). Binge eating and dietary restraint in obese patients. Addictive Behaviors, 10, 163-168.

Marlatt, G. A., \& Gordon, J. R. (1985). Relapse Prevention: Maintenance strategies in the treatment of addictive behaviors. New York: Guilford Press. 
Miller, C. T., \& Downey, K. T. (1999). A meta-analysis of heavyweight and self-esteem. Personality and Social Psychology Review, 3, 68-84.

Mussell, M. P., Mitchell, J. E., DeZwaan, M., Crosby, R. D., Seim, H. C., \& Crow, S. J. (1996). Clinical characteristics associated with binge eating in obese females: A descriptive study. International Journal of Obesity, 20, 324-331.

Omer, H., \& London, P. (1989). Signal and noise in psychotherapy: The role and control of nonspecific factors. British Journal of Psychiatry, 155, 239-245.

Perri, M. G., McAdoo, W. G., McAllister, D. A., Lauer, J. B., Jordan, R. C., \& Nezu, A. M. (1981). Effects of peer support and therapist contact on long-term weight loss. Journal of Consulting and Clinical Psychology, 55, 615-617.

Perri, M. G., Nezu, A. M., Patti, E. P., \& McCann, K. L. (1989). Effect of length of treatment on weight loss. Journal of Consulting and Clinical Psychology, 57, 450-452.

Polivy, J., \& Herman, C. P. (1992). Undieting: A program to help people stop dieting. International Journal of Eating Disorders, 11, 261-268.

Porzelius, L. K., Houston, C., Smith, M., Arfken, C., \& Fisher, E. (1995). Comparison of a standard behavioral weight loss treatment and a binge eating weight loss treatment. Behavior Therapy, 26, 119-134.

Rosenberg, M. (1965). Society and the adolescent self-image. Princeton, NJ: Princeton University Press.

Rossiter, E. M., Agras, W. S., Telch, C. F., \& Bruce, B. (1992). The eating patterns of non-purging bulimic subjects. International Journal of Eating Disorders, 11, 111-120.

Spitzer, R., Devlin, M., Walsh, B. T., Hasin, D., Wing, R., Marcus, M., Stunkard, A., Wadden, T., Yanovski, S., Agras, S., Mitchell, J., \& Nonas, C. (1992). Binge eating disorder: A multisite field trial of the diagnostic criteria. International Journal of Eating Disorders, 11, 191-203.

Telch, C. F., \& Agras, W. S. (1993). The effects of a very low calorie diet on binge eating. Behavior Therapy, 24, $177-193$.

Telch, C. F. \& Agras, W. S. (1994). Obesity, binge eating and psychopathology: Are they related? International Journal of Eating Disorders, 15, 53-61.

Telch, C. F., Agras, W. S., \& Rossiter, E. M. (1988). Binge eating increases with increasing adiposity. International Journal of Eating Disorders, 7, 115-119.

Wadden, T. A. (1993). Treatment of obesity by moderate and severe restriction: Results of clinical research trials. Annals of Internal Medicine, 119, 688-693.

Wadden, T. A., Foster, G. D., \& Letizia, K. A. (1994). One-year behavioral treatment of obesity: Comparison of moderate and severe caloric restriction and the effects of weight maintenance therapy. Journal of Consulting and Clinical Psychology, 62, 165-171.

Wardle, J. (1995). The assessment of obesity: Theoretical background and practical advice. Behaviour Research and Therapy, 33, 107-117.

Wilfley, D. E., Agras, W. S., Telch, C. F., Rossiter, E. M., Schneider, J. A., Cole, A. G., Sifford, L., \& Raeburn, S. D. (1993). Group cognitive-behavioral therapy and group interpersonal psychotherapy for the nonpurging bulimic individual: A controlled comparison. Journal of Consulting and Clinical Psychology, 61, $296-305$.

Wilfley, D. E., \& Cohen, L. R. (1997). Psychological treatment of bulimia nervosa and binge eating disorder. Psychological Bulletin, 33, 437-454.

Wilfley, D. E., Schwartz, M. B., Spurrell, E. B., \& Fairburn, C. F. (1997). Assessing the specific psychopathology of binge eating disorder patients: Interview or self-report? Behaviour Research and Therapy, 35, 1151-1159.

Wilson, G. T. (1994). Behavioral treatment of obesity: Thirty years and counting. Advances in Behaviour Research and Therapy, 16, 31-75.

Wilson, G. T., Nonas, C. A., \& Rosenblum, G. D. (1993). Assessment of binge eating in obese patients. International Journal of Eating Disorders, 13, 25-33.

Yanovski, S. Z. (1993). Binge eating disorder: Current knowledge and future directions. Obesity Research, 1, 306-324.

Yanovski, S. Z., Nelson, J. E., Dubbert, B. K., \& Spitzer, R. L. (1993). Association of binge eating disorder and psychiatric comorbidity in obese subjects. American Journal of Psychiatry, 150, 1472-1479. 